\title{
Clinical Anatomy of the Mandible of Three Marsupial Species (Koala, Wombat, Wallaby)
}

\author{
A. S. Saber*
}

*Faculty of Veterinary Medicine, University of Sadat City, Sadat City, Egypt \& Discipline of Veterinary Sciences, College of Public Health, Medical and Veterinary Sciences, James Cook University, Townsville, Australia

With 5 figures, 2 tables $\quad$ Received October, accepted for publication December 2014

\section{Abstract}

Marsupials are an infraclass of mammals living primarily in Australasia and the New World. Well-known marsupials include kangaroos, wallabies, koala, possums, opossums, wombats and the Tasmanian devil. Three species, the koala, wombat and wallaby were chosen for this study. Three Koala (Phascolarctos cinereus), two wombat (Vombatus ursinus) and three Grey's wallaby (Macropus greyi) mandibles, were used for this morphometric study. Twelve measurements were taken for each mandible with the aim of evaluating some morphometric parameters in these three species and its clinical implication during regional anesthesia. The craniometric measurements were taken using a normal caliper. Photographs were taken by a Samsung digital camera WB 700. Nomina Anatomica Veterinaria (2005) was utilized for denominating the anatomical terms in the study. The results were supported by 9 Figures and 2 Tables.

\section{Introduction}

Marsupials are an infraclass of mammals living primarily in Australasia and the New World. A distinctive characteristic, common to most species, is that the young are carried in a pouch. Well-known marsupials include kangaroos, wallabies, koala, possums, opossums, wombats and the Tasmanian devil. Less well-known species of marsupials include the numbat, bandicoots, bettongs, the bilby, quolls and the quokka ${ }^{1}$.

Close to $70 \%$ of the 334 extant species occur in Australia, New Guinea, and nearby islands. Three species, the koala, wombat and wallaby were chosen for this study as they are kept in the wildlife sanctuaries and zoos in Australia as attractions and representative of the Australian marsupials. These marsupials may suffer many infections, injuries and diseases. The Chidlow Marsupial Hospital located in Perth listed some infections of the head region such as the oedema, ear discharge and debris, eye infections and injuries, cracked nostrils, nasal 
bleeding and discharge and different mouth infections ${ }^{2}$.

It is quite clear that the morphologic and morphometric investigations on the skull/ mandible not only reflect contributions of genetic and environmental components to individual development, but are also foundations of the clinical and surgical practice (Karimi et al., 2011 and Wehausen and Ramey, 2000). Many geometrical measure-ments of the skull bones have been used for species determination in ruminants in particular (Sarma, 2006; Yalçin and Kaya, 2009; Yalçin and Lök 2009; Karimi et al., 2011; Karimi et al., 2012). In addition, applied anatomy is one of the principals of clinical and surgical practice; because it enables the clinician to visualize details of structures relevant to the case at hand (Ommer and Harshan, 1995 \& Dyce et al., 2002). Similarly, the distribution of the cranial nerves and their passages from different foramina in the skull are of clinical importance in regional anesthesia for surgical purposes (Dyce et al., 2002 \& Hall et al., 2000).

Since there is no information about the applied anatomy of these marsupial species in the available literatures, the aim of this work is to evaluate some morphometric parameters of the mandible in these three species and its clinical implication during regional anesthesia.
Keywords: Koala (Phascolarctos cinereus), Wallaby (Macropus greyi), Wombat (Vombatus ursinus), clinical anatomy, mental foramen, mandibular foramen, morphometery.

\section{Material and Methods}

Three Koala (Phascolarctos cinereus), three Grey's wallaby (Macropus greyi) and two wombat (Vombatus ursinus) skulls including the mandibles, kept in the Discipline of Anatomy and Pathology, School of Veterinary and Biomedical Sciences, James Cook University, Townsville, Australia, were used in this study. The measurements taken for the mandibles included:

1. Mandibular length (distance between the level of the rostral part of the alveolar root of the incisor to the level of the caudal border of the mandible).

2. Mandibular weight.

3. Distance between caudal mental foramen and caudal mandibular border.

4. Distance between caudal mental foramen and rostral mental foramen.

5. Distance between rostral mental foramen and incisor root.

6. Distance between mandibular foramen and caudal border of the mandible. 
7. Distance between mandibular foramen and angle of the mandible.

8. Maximum mandibular height (distance between the basal point of the mandible to the highest level of the coronoid process)

9. Condyloid process to the caudal border (base) of the mandible.

10. Maximum height of coronoid process (condyloid fossa to height of mandible).

11. Mandibular foramen to base of the mandible.

12. Diastema length: distance from the lateral alveolar incisor root to first cheek tooth (P).

The craniometric measurements were taken using a normal caliper, and a digital scale was used for weighing. Photographs were taken by a Samsung digital camera WB 700. Nomina Anatomica Veterinaria (2005) was utilized for denominating the anatomical terms in the study.

\section{Results}

The mandible comprises two rami firmly fused together at the mandibular symphysis. This fusion is remarkably very rigid in koala, less in wombat and weak in wallaby. The masseteric fossa is deep in koala and is bounded by prominent rostral and caudal borders. Only koala has two mental foramina, the rostral one lies J. Vet. Anat. in front of the premolar $(P)$, while the caudal one lies under $\mathrm{M}_{2}$. In wombat and wallaby, the mental foramen lies at the level in front of the premolar $(P)$ (Figs 1-4). Moreover, the wombat has an extra mental foramen on each side, situated on the ventral surface of the body of the mandible about 1.5 $\mathrm{cm}$ from the root of the incisor. In one right mandible, many ventral mental foramina were detected (Fig 3/B).

In the present study, the mandible length in koala, wombat and wallaby was $9.8 \pm 5.66, \quad 12.7 \pm 8.89$ and $9.9 \pm 5.72 \mathrm{~cm}$ and the mandible height was $6.8 \pm 3.93, \quad 8.03 \pm 5.69$ and $4.1 \pm 2.37 \mathrm{~cm}$ respectively. The mandibular weight was $26 \pm 15.01$, $137 \pm 96.87$ and $35 \pm 24.75 \mathrm{gm}$. respectively. Furthermore, the distance between (caudal) mental foramen and caudal mandibular border and between the (rostral) mental foramen and incisor root was 5.8 \pm 3.18 , $9.75 \pm 6.31$ and $8.2 \pm 4.73 \mathrm{~cm}$ and $1.3 \pm 0.75,2.2 \pm 1.56$ and $1.7 \pm 0.98 \mathrm{~cm}$ in the koala, wombat and wallaby respectively. Only the koala posses two mental foramina, rostral and caudal; with a distance of $2.4 \mathrm{~cm}$ between them (Table 1, Fig 2)

The distance between the condyloid process to the base of the mandible and the maximum height of coronoid process in koala, wombat and wallaby was $5.7 \pm 3.29,6.75 \pm 4.78$ and $4.2 \pm$ $2.42 \mathrm{~cm} \& 1.13 \pm 0.65,1.3 \pm 0.92$ and $2.1 \pm 1.21 \mathrm{~cm}$ respectively. While, the 
distance between the mandibular foramen to base of the mandible was $2.6 \pm 1.84,2.25 \pm 1.50$ and $0.8 \pm 0.57 \mathrm{~cm}$ and between the mandibular foramen and caudal border (base) of the mandible was $1.3 \pm 0.75,2.1 \pm 1.48$ and $2.7 \pm 1.56 \mathrm{~cm}$ and between the mandibular foramen and angle of the mandible was $2.3 \pm 1.63,3.05 \pm 2.16$ and $1.2 \pm 0.69 \mathrm{~cm}$ in koala, wombat and wallaby respectively (Table 1, Fig 5).

\section{Discussion}

Beddard (1958) mentioned that the mandible in marsupials is inflected; this familiar charachteristic of the marsupials goes back to the earliest representatives of the order in Mesozoic times; but it is not absolutely universal, being absent from the much weakened skull of Tarsipes (honey possum).

According to Lieberman and Crompton (2000), animals that have unfused mandibles like the goat (and wallabies of this study to some extent) not only have a ratio of working to balancing side adductor muscle force of $1: 1$ but they also have their mandibles rotate independently during occlusion.

The mandibular length and height measured for koala, wombat and wallaby of this study were $9.8 \pm 5.66$, $12.7 \pm 8.89,9.9 \pm 5.72 \mathrm{~cm}$ \& $6.8 \pm 3.93$, $8.05 \pm 5.69,4.1 \pm 2.37 \mathrm{~cm}$ respectively. Barroso et al. (2009) mentioned 51.47 $\pm 4.02 \mathrm{~mm}$ as length of non defined cat breed's mandible, Samul et al. (2013) mentioned in goats 13.61士 1.73 and $8.5 \pm 0.53 \mathrm{~cm}$ for the length and height of the mandible respectively, while Monfared (2013i) gave $8.3 \pm 1.03$ and $3.7 \pm 0.59 \mathrm{~cm}$ as length and height for the Persian cat's mandible.

The distance between the lateral alveolar root to mental foramen was $1.3 \pm 0.75,2.2 \pm 1.56$ and $1.7 \pm 0.98 \mathrm{~cm}$ in the Koala, wombat and wallaby respectively. This parameter is a vital guide that will allow detection of the location of the mental nerve for the regional nerve block in these animals; especially for lower lip anesthesia. The injection of the local anesthetic agents can be made in the rostral aspect of the mandibular canal through the mental foramen to mandibular nerve block in the mental zone. This will ensure the loss of sensation of the lower incisors, premolar and lower lip on the same side (Hall et al. 2000) during lower lip trauma, dental extraction and treatment of the tooth injuries. Extra mental foramen found in wombat of this study was also described in dog by Popesko (1977) and Evans and De Lahunta (2010), in one-humped camel by Monfared (2013c) as well as in man by Balcioglu and Kocaelli (2009).

The distance between the mandibular foramen to caudal border of the mandible was $1.3 \pm 0.75,2.1 \pm 1.48$ and 
$2.7 \pm 1.56 \mathrm{~cm}$ in koala, wombat and wallaby respectively. In addition, the distance between mandibular foramen and angle of the mandible and the ventral border (base) of the mandible was $2.3 \pm 1.63,3,05 \pm 2.16$ and $1.2 \pm 0.69 \mathrm{~cm} \& 2.6 \pm 1.84,2.25 \pm 1.50$ and $0.87 \pm 0.57$ respectively. Comparative lengths of both distances in different animals species studied were given in table (2). Accordingly, the anesthetic agent must be injected on the medial side of the mandible for blocking the mandibular nerve and achieving the regional anesthesia of the lower jaw with its teeth and the mandibular lip and this also in agreement with Flecknell (1980) and Hall et al., (2000). This view agrees with that of Monfared (2013a-k) in Caspian Miniature horse, Iranian native cattle, one-humped camel, Native sheep, Native horse, Iranian buffalo, dog, rabbits, Golden jackal, Persian cat and native donkey; Olopade et al., (2005) in West African Dwarf Goat; and Olopade et al., (2010) in Red Sokoto and Sahel goats.

In conclusion, the morphometric values of the mandibles and the clinical anatomy of the three marsupials; koala, wombat and wallaby mandibles provide an important baseline for further research in the comparative anatomy. Furthermore, the results obtained could be a useful tool that will aid the regional anesthesia of the cranial nerves around the head especially during treating head injury and

J. Vet. Anat. dental extraction and approach of these species.

\section{References}

Balcioglu, H.A. and Humeyra Kocaelli, H. (2009): Accessory mental foramen. North American Journal of Medical Sciences, Vol. 1, No. 6: 314-315.

Beddard, F. (1958): Mammalia, Vol. X. a reprint edition from 1902, by Macmillan \& Co., Limited

Dyce, K.M., Sack, W.O. and Wensing, C.J.G. (2002): Textbook of Veterinary Anatomy, ed 3. Philadelphia, W.B. Saunders.

Evans, H.E. and de Lahunta, A. (2010): Guide to the dissection of the dog. $7^{\text {th }}$ ed., Sauders, Elsevier.

Flecknell, P.A. (1980): Laboratory animal anesthesia. Academic press limited. London, pp: 137.

Hall, L.W., Clarke, K.W. and Trim, C.M. (2000): Wright's Veterinary Anesthesia and Analgesia. 10. ed. London, ELBS and Baillierre Tindall.

Karimi,I.; Hadipour, M.; Nikbakht, P. and Motamedi, S. (2012): The lower Jawbone of Mehraban Sheep: A Descriptive Morphometric Approach. World's Vet. J. 2(4): 57-60

Karimi, I.; Onar, V.; Pazvant, G.; Hadipour, M.M. and Mazaheri, Y. 
(2011): The cranial morphologic characteristics of Mehraban sheep in western Iran. Global Veterinaria 6 (2): 111-117.

Lieberman, D.E, and Crompton, A.W. (2000): Why fuse the mandibular symphysis? A comparative analysis? Am. J. Phys. Anthropol., 122: 517-540

Monfared, A.L. (2013a): Some Aspects of Clinical Anatomy of the Head Region of the Caspian Miniature Horse and its Clinical Value During Regional Anesthesia. Global Veterinaria 10 (2): 214-218.

Monfared, A.L. (2013b): Gross Anatomical Measurements of the Head Region of the Iranian Native Cattle (Bos taurus) and Their Clinical Value for Regional Anesthesia. Global Veterinaria 10 (2): 219-222.

Monfared, A.L. (2013c): Clinical Anatomy of the Skull of Iranian Native Sheep. Global Veterinaria 10 (3): 271275.

Monfared, A.L. (2013d): Applied anatomy of the head regions of the One-humped camel (Camelus dromedaries) and its clinical implications during regional anesthesia. Global Veterinaria 10 (3): 322-327.

Monfared, A.L. (2013e): Gross Anatomy of the Head Region of the Iranian Native Horse and its Clinical Value
During Regional Anesthesia. Global Veterinaria 10 (4): 403-407..

Monfared, A.L. (2013f): Craniometrical and gross Anatomical Studies on the Iranian Buffaloes and Their Clinical Value for Regional Anesthesia. Global Veterinaria 10 (4): 427-431.

Monfared, A.L. (2013g): Anatomical study of the skull of the adult dogs and its Clinical Value During Regional Anesthesia. Global Veterinaria 10 (4): 459-463.

Monfared, A.L. (2013h): Macroanatomical Investigation of the Skull of Golden Jackal (Canis aureus) and its clinical Application during Regional Anethesia. Global Veterinaria 10 (5): 547-550.

Monfared, A.L. (2013i): Anatomy of the Persian Cat's skull and its clinical value during regional anesthesia. Global Veterinaria 10 (5): 551-555.

Monfared, A.L. (2013j): Applied Anatomy of the Rabbit's Skull and its Clinical Application During Regional Anesthesia. Global Veterinaria 10 (6): 653-657

Monfared, A.L. (2013k): anatomy of the head region of the Iranian native donkeys and its clinical value during regional anesthesia. Global Veterinaria 10 (6): 658-662. 
NAV (2005): Nomina Anatomica Veterinaria, International Committee on Veterinary Gross Anatomical Nomenclature. $5^{\text {th }}$ Ed. Pub. By the Ed. Com. Hannover, Columbia, Gent, Supparo, USA.

Olopade, J.O. and Okandeji, M.E. (2005): A study of some rostrofacial indices related to regional anaesthesia of the porcine: Implication as an animal model for dental research. Nig. J. Physiol. Sci., 25: 159-164.

Olopade, J.O. and Onwuka, S.K. (2005): Some aspects of the clinical anatomy of the mandibular and maxillofacial regions of the West African Dwarf Goat in Nigeria. Int. J. Morphol. 23(1): 33-36.

Olopade, J.O.; Samuel, M.O.; Antia, R.E. and Onwuka, S.K. (2010): Maxillofacial and mandibular phenotypes in the skulls of Red Sokotos and Sahel goats in Nigeria: The role of dental abnormalities.

Ommer, P.A. and Harshan, K.R. (1995): Applied anatomy of domestic' animals, 1st Edition. Jaypee brother's medical publiser, India.

Popesko, P. (1977): Atlas of Topographical Anatomy of the Domestic Animals, $2^{\text {nd }}$ ed. Philadelphia, Sauders.

Samul, O. M., Olopsde, J. O., Korzerzer, M. R., and Onwuka, S. J. Vet. Anat.
K.(2013): Craniometric evaluation of some cranial indices of clinical significance in goats (Capra Hircus) from the Middle-Belt Region of Nigeria case for population surveillance and ecomigration. European Journal of Zoological Research, 2013, 2 (4):8997.

Sarma, K. (2006): Morphological and craniometrical studies on the skull of kagani goat (Capra hircus) of Jammu Region. Int. J. Morphol., 24(3): 449455.

Uddin, M.M., Ahmed, S.S.U., Islam, Kh. N. and Islam, Md. M. (2009): Clinical anatomy of the head region of the Black Bengal goat in Bangladish. Int. J. Morphol., 27(4):1269-1273.

Yalçin, H. and Lök, S. (2009): Anadolu Yaban Koyunu (Ovis gmelini anatolica) ve Akkaraman Koyununun (Ovis aries) Kafa Kemikleri Üzerinde Karşilaştirmali Makro -Anatomikatomik Arastirma. Atatürk Üniv. Vet. Bil. Derg. 4(3): 147-162.

Yalçin, H. and Kaya, M.A. (2009): Anadolu Yaban Koyunu ve Akkaraman Koyununun Kafa Kemikleri Üzerinde Karşilaştirmali Geometrik Morfometri. Atatürk Üniv. Vet. Bil. Derg. 4(2): 105-116.

Wehausen, J.D. and Ramey, R.R. (2000): Cranial morphometric and evolutionary relationships in the northern range of Ovis canadensis. 
Journal of Mammalogy, 81: 145-161.

\section{Websites:}

1) http://en.wikipedia.org/wiki/Ma rsupial (Retrieved 16/2/2014)
2) http://www.chidlowmarsupialh ospital.org.au/page-44-1common-injuries.html. (Retrieved 16/2/2014)

Author's address:

Prof. Dr. Ashraf S. Saber

Dept. of Anatomy \& Embryology

Faculty of Veterinary Medicine,

University of Sadat City, Sadat City, Egypt.

E-mail: saberasbraf 2@yahoo.com

Table (1): Mean and Standard deviation (SD) of the mandible measurements of the kola, wombat and wallaby.

\begin{tabular}{|c|l|c|c|c|c|c|c|}
\hline No & Parameters /cm & $\begin{array}{c}\text { Koala/ } \\
\text { mean }\end{array}$ & $\begin{array}{c}\text { Koala/ } \\
\text { SD }\end{array}$ & $\begin{array}{c}\text { Wombat } \\
/ \text { mean }\end{array}$ & $\begin{array}{c}\text { Wombat/ } \\
\text { SD }\end{array}$ & $\begin{array}{c}\text { Wallaby } \\
\text { / mean }\end{array}$ & $\begin{array}{c}\text { Wallaby/ } \\
\text { SD }\end{array}$ \\
\hline 1 & Mand.Length & 9.8 & 5.66 & 12.7 & 8.89 & 9.9 & 5.72 \\
\hline 2 & Mand.Weight (gm) & 26 & 15.01 & 137 & 96.87 & 35 & 24.75 \\
\hline 3 & C Ment. For - C Mand. B & 5.8 & 3.18 & 9.75 & 6.31 & 8.2 & 4.73 \\
\hline 4 & C Ment. For - R Ment.For. & 2.4 & 1.39 & - & - & - & - \\
\hline 5 & R Ment. For - Incis. Root & 1.3 & 0.75 & 2.2 & 1.56 & 1.7 & 0.98 \\
\hline 6 & Mand. For - C B Mand. & 1.3 & 0.75 & 2.1 & 1.48 & 2.7 & 1.56 \\
\hline 7 & Mand F - Mand. Ang. & 2.3 & 1.63 & 3.05 & 2.16 & 1.2 & 0.69 \\
\hline 8 & Mand. Height & 6.8 & 3.93 & 8.05 & 5.69 & 4.1 & 2.37 \\
\hline 9 & Condyl.Pr -Ven.Bor.Mand. & 5.7 & 3.29 & 6.75 & 4.78 & 4.2 & 2.42 \\
\hline 10 & Max.Height Corono. Pros. & 1.13 & 0.65 & 1.3 & 0.92 & 2.1 & 1.21 \\
\hline 11 & Mand.For. -Ven.Bor.Mand. & 2.6 & 1.84 & 2.25 & 1.50 & 0.8 & 0.57 \\
\hline 12 & Diastema Length & 1.7 & 0.98 & 2.57 & 1.94 & 2.0 & 1.15 \\
\hline
\end{tabular}


Table (2): Measurements between the mandibular foramen (Mand. For.) and caudal border of the mandible and betweem mandibular foramen and ventral border (base) of the mandible in some animal species.

\begin{tabular}{|c|c|c|c|}
\hline Animals & Authors & $\begin{array}{c}\text { Mand. For. To caudal } \\
\text { border of mandible }(\mathrm{cm})\end{array}$ & $\begin{array}{c}\text { Mand. For, to ventral } \\
\text { border of mandible (cm) }\end{array}$ \\
\hline Caspian Miniature horse & Monfared (2013a) & $4.4 \pm 0.03$ & $5.79 \pm 0.57$ \\
\hline Iranian native cattle & Monfared (2013b) & $2.9 \pm 0.72$ & $5.2 \pm 0.37$ \\
\hline One-humped camel & Monfared (2013c) & $3.7 \pm 0.11$ & $3.88 \pm 0.37$ \\
\hline Native sheep & Monfared (2013d) & $0.86 \pm 0.03$ & $2.99 \pm 0.03$ \\
\hline Native horse & Monfared (2013e) & $4.8 \pm 0.62$ & $6.3 \pm 1.34$ \\
\hline Iranian buffalo & Monfared (2013f) & $2.97 \pm 0.26$ & $5.5 \pm 0.31$ \\
\hline Dog & Monfared (2013g) & $1.1 \pm 0.09$ & $0.96 \pm 0.57$ \\
\hline rabbit & Monfared (2013h) & $1.51 \pm 0.23$ & $0.87 \pm 0.09$ \\
\hline Golden jackal & Monfared (2013i) & $1.05 \pm 0.02$ & $0.8 \pm 0.66$ \\
\hline Persian cat & Monfared (2013j) & $0.65 \pm 0.36$ & $4.7 \pm 1.22$ \\
\hline Native donkey & Monfared (2013k) & $3.5 \pm 0.02$ & - \\
\hline West African dwarf goat & Olopade et al. (2005) & $1.57 \pm 0.44$ & $9.34 \pm 0.95$ \\
\hline pig & Olopade and Okandeji & $2.83 \pm 0.34$ & $3.64 \pm 0.23$ \\
\hline Black Bengal goat & Uddin et al., (2009) & $0.9 \pm 0.15$ & $4.17 \pm 1.03$ \\
\hline goat & Samuel et al., (2013) & $2.54 \pm 0.56$ & $2.6 \pm 1.84$ \\
\hline Koala & Saber (2014) this study & $1.3 \pm 0.75$ & $2.25 \pm 1.50$ \\
\hline Wombat & Saber (2014) this study & $2.1 \pm 1.48$ & $0.87 \pm 0.57$ \\
\hline Wallay & Saber (2014) this study & $2.7 \pm 1.56$ & \\
\hline
\end{tabular}

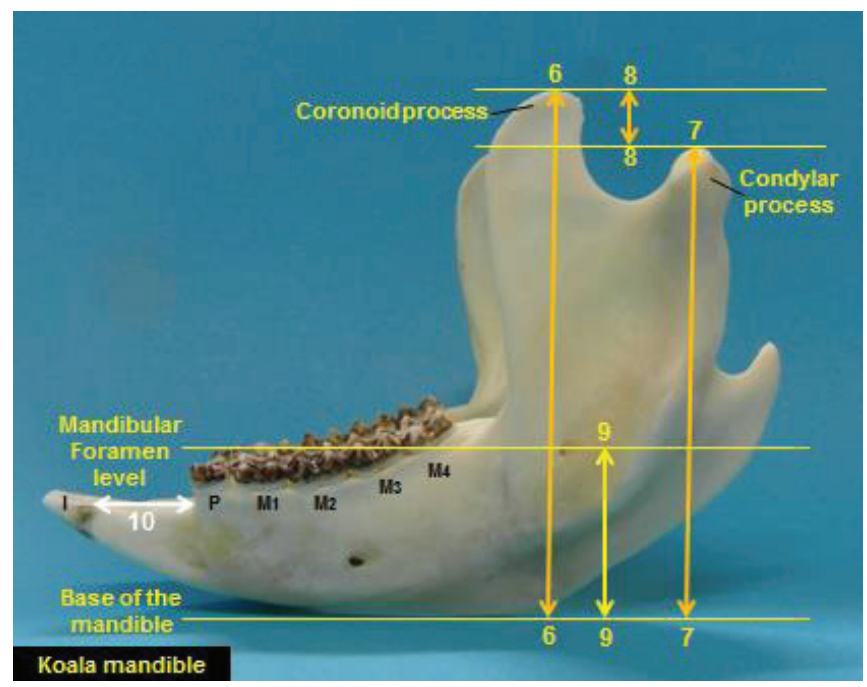

Fig (1): Lateral view of the koala mandible showing: 6-6 Maximum height of the mandible, 7-7 Condyloid process to the base of the mandible, 8-8 condyloid process to coronoid process (Condyloid fossa to hight of mandiblr), 9-9 Mandibular foramen to ventral border (base) of the mandible 10 diastema length between alveolus of the incisor and that of the premolar. 


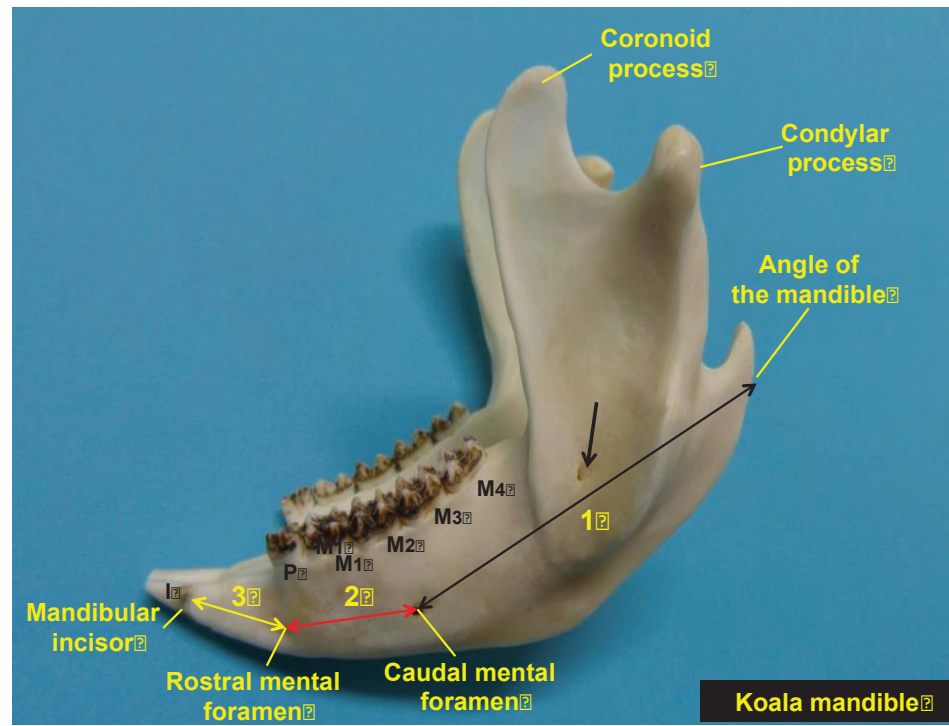

Fig (2): Lateral view of the koala mandible showing: 1 distance between the caudal mental foramen and angle of the mandible, 2 distance between the caudal and rostral mental foramina, 3 distance between rostral mental foramen and the incisor. Arrow indicates extra foramen in the masseteric fossa.
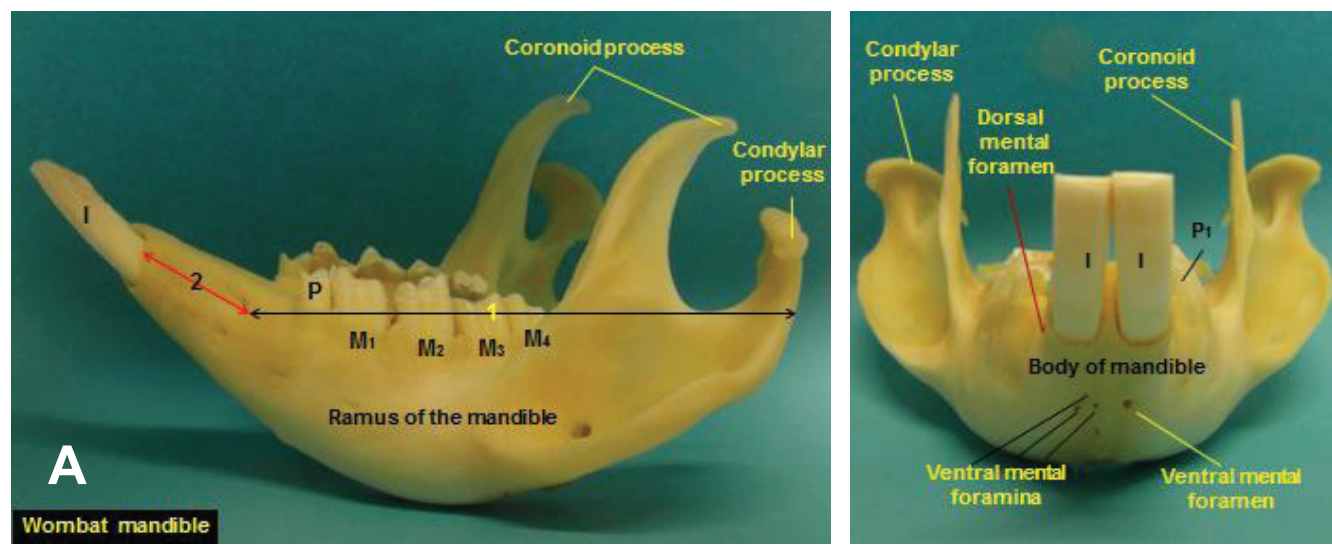

Fig (3): (A) Lateral view of the wombat mandible showing: 1 distance between mental foramen and angle of the mandible, 2 distance between mental foramen and the incisor,

(B) Rostral view of the mandible of wombat showing the ventral mental foramen which is found ventral to the incisors and may be more than one in the same animal. 


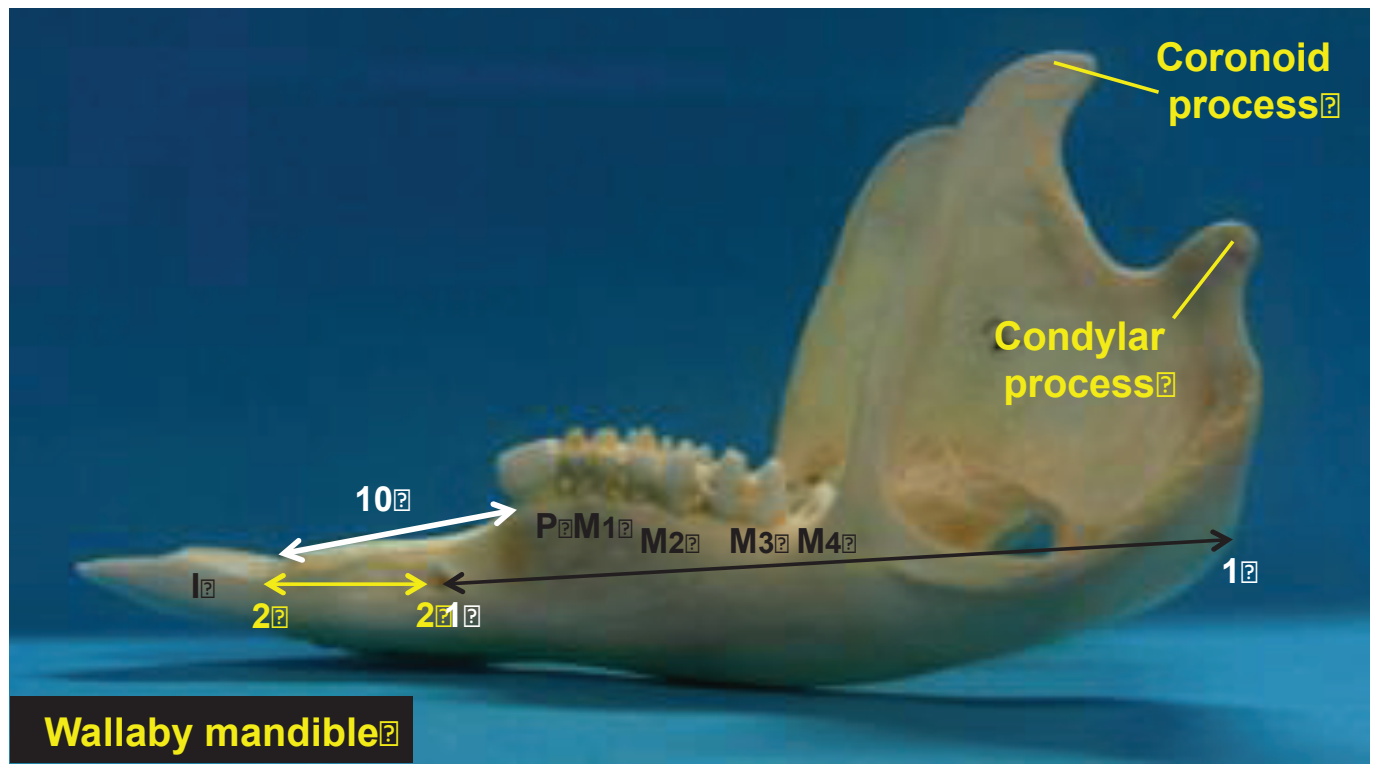

Fig (4): (A) Lateral view of the wallaby mandible showing: 1-1 distance between mental foramen and angle of the mandible, 2-2 distance between mental foramen and the incisor, 10 diastema length

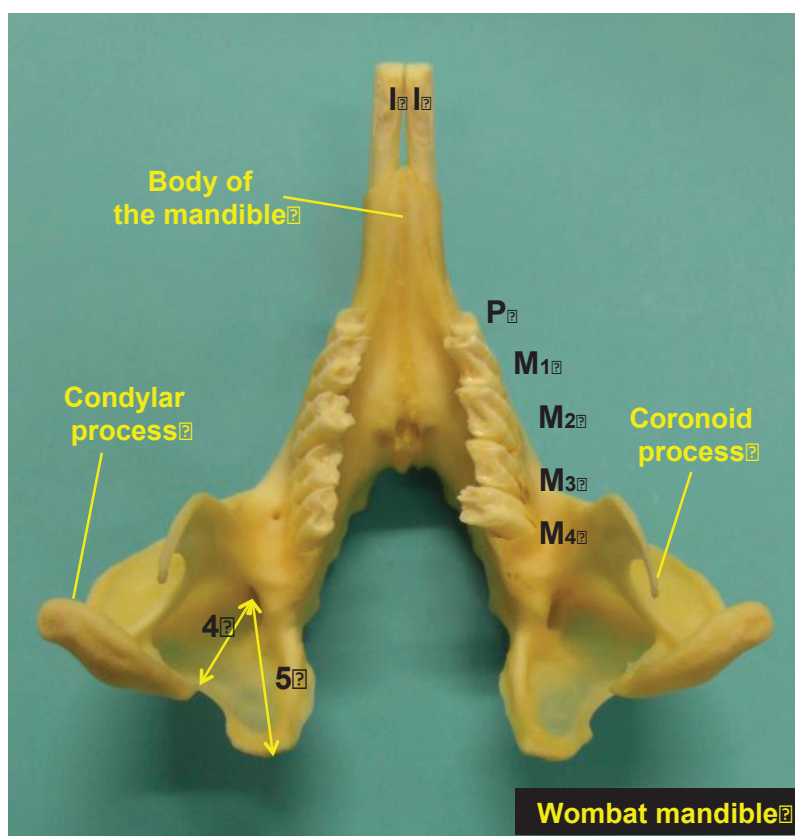

Fig (5): Caudal view of the wombat mandible showing the mandibular foramen. 4 distance between mandibular foramen and caudal border of the mandible, 5 distance between mandibular foramen and angle of the mandible.

J. Vet. Anat.

Vol. 8, No. 1, (2015) 1 - 11 